\title{
Simulation of energy recovery system for power generation form coal bed gas of Tabas coal mine of Iran
}

\author{
H.Farzaneh ${ }^{*}$, M.Fahimi \\ Science and Research Branch, Islamic Azad University, Tehran, Iran \\ * Corresponding author. Tel: +982144865320, Fax: +982144865003, E-mail: info@hfarzaneh.com
}

\begin{abstract}
Coal mine methane is a general description for all methane released prior to, during and after mining operations. As such, there is considerable variability in flow rate and composition of the various gas emissions during mining operations. It would be highly desirable to recover energy from emitted methane of coal mine to generate electricity. Hence, more attention should be focused on the effective utilization of emitted methane in coal mines. The energy recovery system, as one of the promising technologies, has been attracting increased attention to generate electricity from emitted methane in Tabas mine. Some energy recovery systems with different configurations may be proposed such as gas turbine and gas engines. In this investigation, a simulation model has been developed in Hysys software environment to predict generated power from combination of ventilation air and drainage gas (mixture with $1.6 \%$ methane concentration) form Tabas mine by using a leanburn gas turbine.
\end{abstract}

Keywords: Coal bed gas, energy recovery system, lean-burn gas turbine, simulation

\section{Introduction}

New natural gas reserves are vital to guaranteeing a steady supply of affordable fuel to generate electricity and preserve quality of life. Coal bed gas is a form of natural gas reserve which is extracted from coal beds. In recent decades it has become an important source of energy in many countries of the world. It is mainly composed of methane with variable amounts of ethane, nitrogen, and carbon dioxide [1].

A large portion of the methane emitted from coal mines comes from gob areas (collapsed rock over mined-out coal). Coal mines frequently do not use medium-quality gas from gob wells and instead vent the gas to the atmosphere, contributing to global warming. However, gas with a methane concentration exceeding $35 \%$ can in fact be used as a fuel for on-site power generation [2]. Given their large energy requirements, coal mines can recover methane and generate electricity with energy recovery systems to realize significant economic savings and reduce greenhouse gas emissions. Generating electricity is an attractive option because most coal mines have significant electricity loads. Electricity is required to run nearly every piece of equipment including mining machines, conveyor belts, desalination plants, coal preparation plants, and ventilation fans [3].

Coal bed gas methane is emitted in two streams: (1) mine ventilation air (0.1-1\% CH4) and (2) gas drained from the seam before and after mining (60-95\%) CH4. Drainage gas can be utilized to generate electricity directly [4]. For example, internal combustion engines, such as compression fired diesel engines and compression ignition engines modified to be spark-fired engines commonly use drainage gas to generate electricity[5]. The main problem of using drainage gas is related to its periodic extraction from the mine. Also, ventilation air methane is the most difficult source of methane to use as an energy source, as the air volume is large and the methane resource is dilute and variable in concentration and flow rate. Because of low concentration of methane in mine ventilation air, effective technology will be required to utilize it and generate electricity. As brilliant idea, it will be possible to combine ventilation air and drainage gas and produce mixture with sufficient concentration of methane. The 
mixture then can be used as fuel in low concentration methane combustion process such as lean-burn gas turbine for on-site power generation in the mine location [6].

In this investigation, a simulation model has been developed in Hysys software environment to predict generated power from combination of ventilation air and drainage methane in an energy recovery system. To this aim, Tabas mine is considered as case study. The results of the simulation model show that the large portion of total electricity demand of the Tabas coal mine can be supplied from the coal bed gas.

\section{Materials and Methods}

\subsection{System description}

There are several technologies that can be used for stationary power generation by directly using drainage gas, namely conventional gas turbines and gas engines or every internal combustion engine. However, it would be expected that variation of methane concentration and amount of the drainage gas should affect the continuous and stable operation of the power generation units.

The mechanism for generation power from ventilation air may be considered in two categories: 1) Catalytic oxidation 2) Thermal oxidation. In general, catalytic combustion is a multi-step process involving diffusion methane to the catalyst surface, adsorption onto the catalyst, reaction, and release of the product species from the catalyst surface and diffusion back into the bulk [7].

Thermal oxidation can be occurred in combustion chamber of lean-burn gas turbine. The leanburn gas turbine is a recuperative gas turbine, which uses heat from the combustion process to preheat the air containing methane to the auto-ignition temperature (in the range 700-1000 C), with the combusted gas being used to drive a turbine. This gas turbine can operate continuously when the methane concentration in air is above $1.6 \%$, which leads to the air being preheated to $700 \mathrm{C}$ before combustion. Therefore, it requires the addition of substantial quantities of methane to the ventilation air to reach adequate methane concentrations from drainage methane. The mixture is preheated by a recuperator to $450 \mathrm{C}$. Then a recuperative combustion chamber uses the hot combustion products to further heat the fuel-air mixture to a point where ignition occurs. The fuel and air mixture is injected through stainless steel tubes into the combustion region. The burnt gas then passes up the outside of the stainless steel tubes to heat incoming air, and then enters into the turbine inlet to drive the turbine. This heat exchange reduces the exit temperature of air to $850 \mathrm{C}$, which is the same as the standard Centaur turbine. With this design, there is a need to use a turbine that has a low combustion temperature [8].

In this paper, Tabas mine is considered as a case study. Tabas mine is located in Yazd Province, $80 \mathrm{~km}$ south of Tabas City of Iran. This mine is the first mechanized coal mine of Iran that is designed by room and pillar method. Overall specifications of the mine are represented in table (1).

Table1. Overall specifications of Tabas Mine

\begin{tabular}{ll}
\hline Total production per year (2009) & 1.2 Millions tones \\
\hline Ventilation air flow rate $(0.18 \%$ CH4 by volume) & $360000 \mathrm{Nm}^{3} / \mathrm{h}$ \\
\hline Drainage gas flow rate $(76.5 \% \mathrm{CH} 4$ by volume) & $2271 \mathrm{Nm}^{3} / \mathrm{h}$ \\
\hline Total installed electricity demand & $10.8 \mathrm{MW}$ \\
\hline
\end{tabular}

Concentration of methane in ventilation air is available by on site measuring system. Figure (1) shows the variation of methane concentration in ventilation air flow during 7 months. 
According to this figure, the higher peak and average value of methane concentration are measured around $0.25 \%$ and $0.18 \%$ respectively. It is clear that, the concentration of methane in ventilation air is not sufficient for burning in combustion chamber of lean-burn gas turbine. Therefore, mixing of certain amount of drainage gas will be required to improve the level of methane concentration up to $1.6 \%$.

Schematic of energy recovery system which may be used for methane recovery in Tabas coal mine is depicted in figure (2). According to this figure, ventilation air and drainage gas are mixed together in the mixer storage and with suitable concentration will be fed into the leanburn gas turbine. It may be possible to use remainder amount of drainage gas in a gas engine for generating excess electricity.

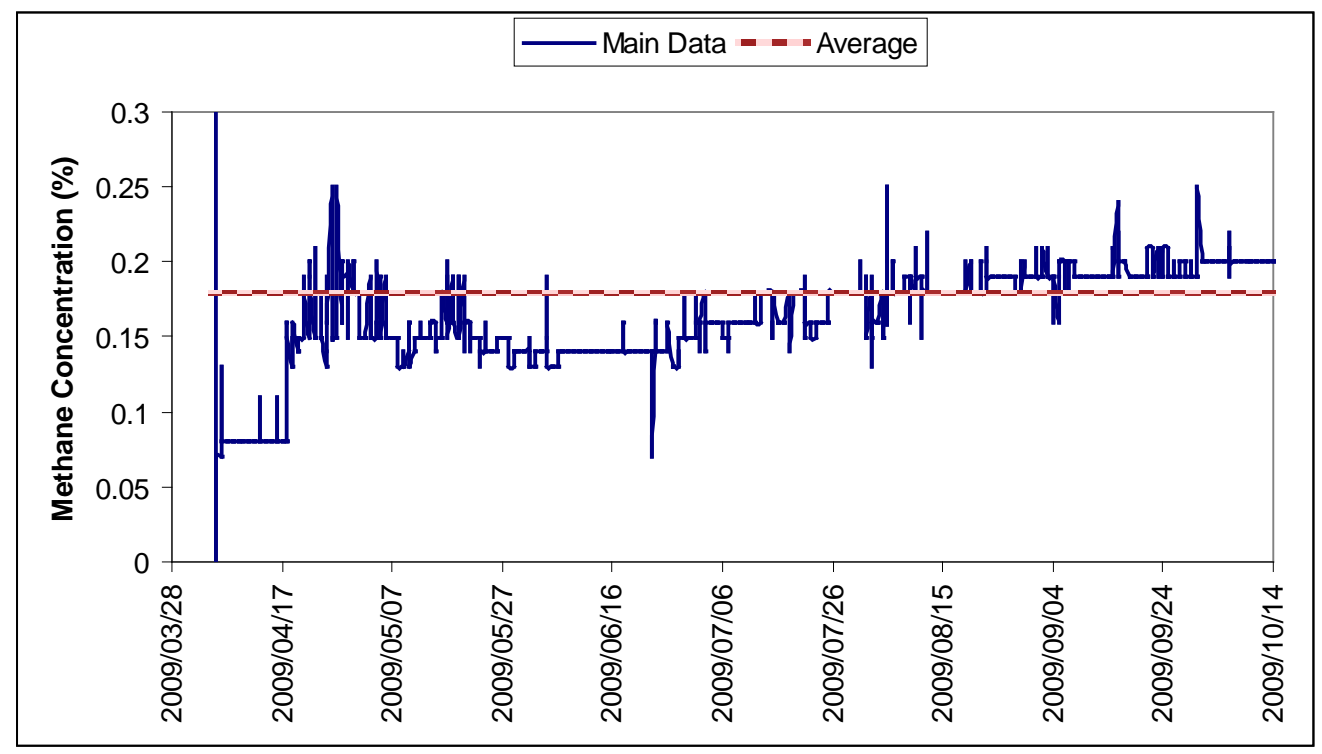

Fig. 1 Variation of methane concentration of ventilation air in Tabas mine

\subsection{Methodology}

The simulation model has been found on the theoretical principles of first and second lows of thermodynamics and it has been tailored to identify the design condition of specified energy recovery system for power generation in Tabas coal mine. To this aim, HYSYS simulator is used. Simulated framework of the energy recovery system in Tabas coal mine is represented in figure (3). While, the methane concentration of ventilation air of Tabas mine is very low, total amount of drainage gas should be consumed for generating power in lean-burn gas turbine cycle. Therefore, no gas engine will be required for excess power generation. Physical properties of streams are approximated by the Peng-Robinson equation of state formula through developing simulation model by HYSYS software [9].

\section{Results and Discussions}

The aforementioned simulation model has been applied for performance analysis of the energy recovery system and estimation total generated power form the energy recovery system in Tabas coal mine. According to represented results in table (2), 6.193 MW power can be generated by the energy recovery system. The thermal efficiency of the cycle is obtained at $24.74 \%$ because of low concentration of methane in the inlet feed of combustion chamber of lean-burn gas turbine. 


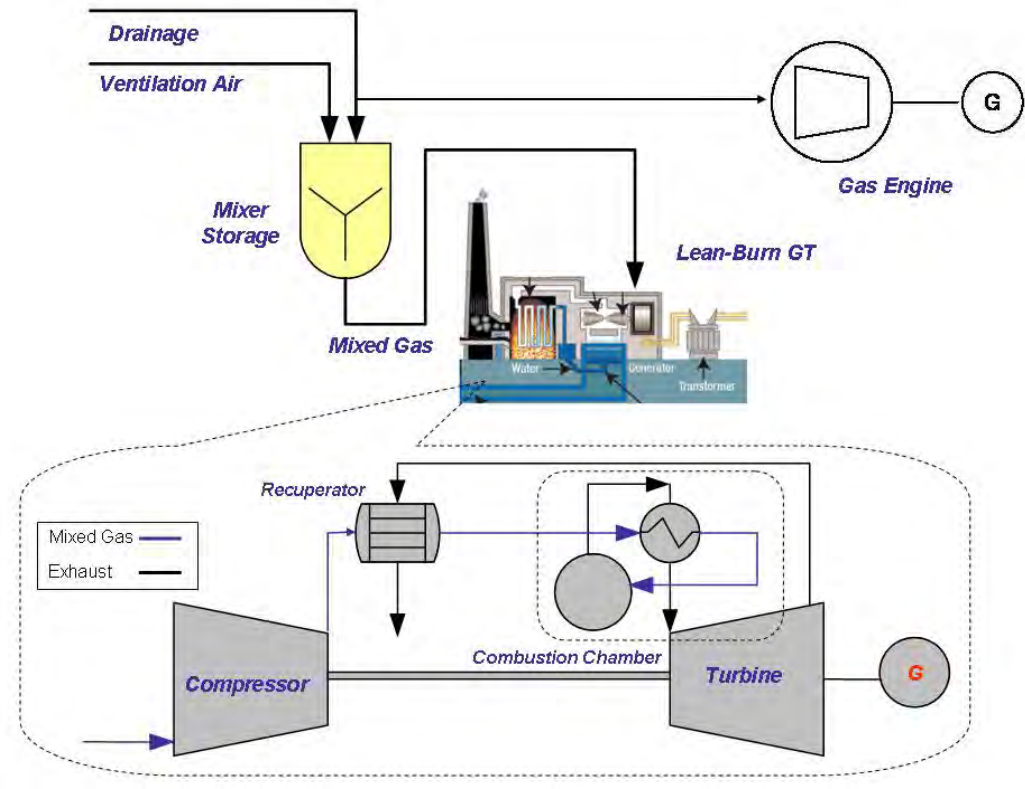

Fig. 2 schematic of energy recovery system in coal mine

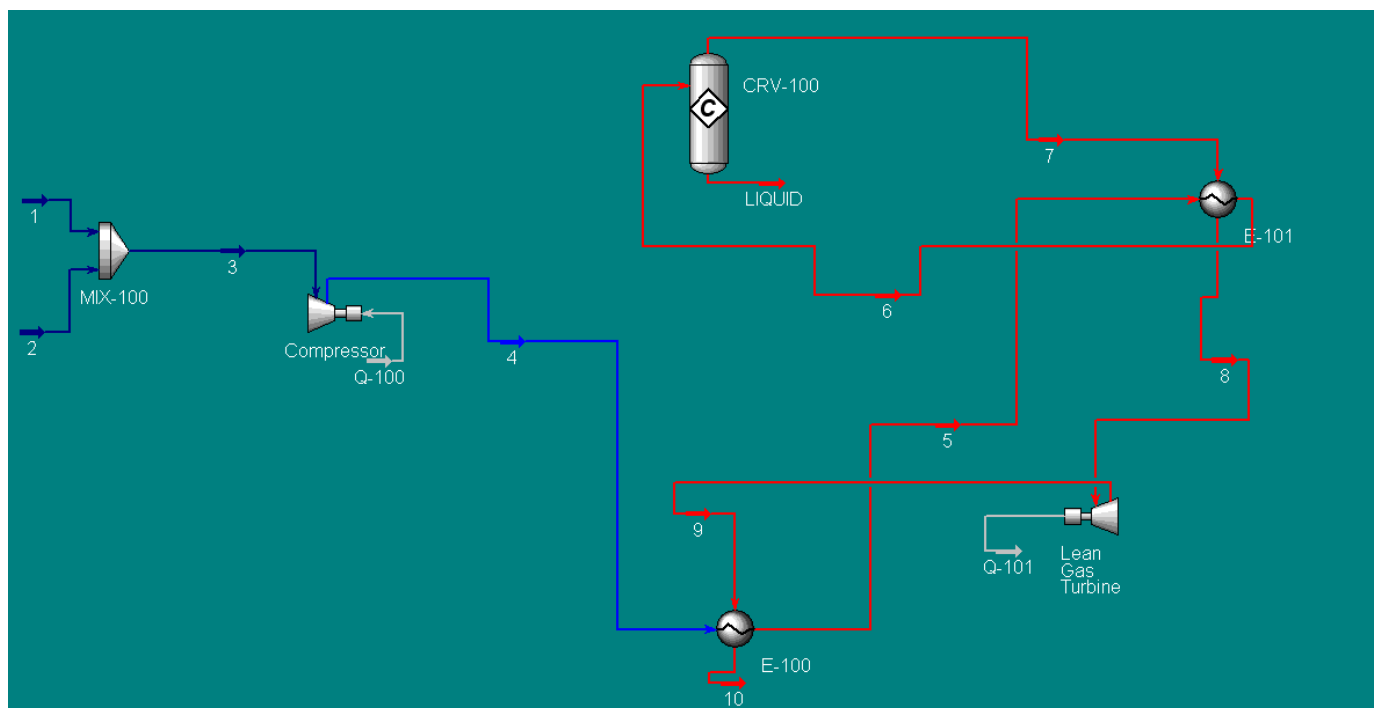

Fig. 3 Simulated frame work of energy recovery system in HYSYS simulator

Table2. Simulation results

\begin{tabular}{lc}
\hline Turbine power generated (MW) & 12.60 \\
\hline Compressor power consumed (MW) & 6.407 \\
\hline Net power generated by cycle (MW) & 6.193 \\
\hline Thermal efficiency of cycle (\%) & 24.74 \\
\hline Usage percentage of ventilation air (\%) & 54 \\
\hline Usage percentage of drainage gas (\%) & 100 \\
\hline
\end{tabular}


According to simulation results, physical properties and flow rate of streams are represented in table (3). Also, compositions of main streams are reported in table (4).

Table3. Physical properties and flow rate of streams

\begin{tabular}{cccccc}
\hline Line & 1 & 2 & 3 & 4 & 5 \\
\hline Temperature(C) & 50 & 25 & 25.57 & 139.3 & 352 \\
\hline Pressure(kPa) & 150 & 150 & 150 & 400 & 350 \\
\hline Flow(kg/h) & 2503 & 194000 & 196503 & 196503 & 196503 \\
\hline Line & 6 & 7 & 8 & 9 & 10 \\
\hline Temperature(C) & 773.5 & 1137 & 738.1 & 538.5 & 334.5 \\
\hline Pressure(kPa) & 300 & 300 & 297 & 106 & 100 \\
\hline Flow(kg/h) & 196503 & 196503 & 196503 & 196503 & 196503 \\
\hline
\end{tabular}

Table4. Composition of main streams

\begin{tabular}{ccccccc}
\hline (Mole Fraction) & $\mathbf{1}$ & $\mathbf{2}$ & $\mathbf{3}$ & $\mathbf{7}$ & $\mathbf{8}$ & $\mathbf{1 0}$ \\
\hline Oxygen & 0.006 & 0.2116 & 0.2078 & 0.176 & 0.176 & 0.177 \\
& & & & & & \\
\hline Nitrogen & 0.16 & 0.7766 & 0.7651 & 0.7651 & 0.7651 & 0.764 \\
& & & & & & \\
\hline Ethane & 0.020 & 0 & 0.0004 & 0.0004 & 0.0004 & 0.0003 \\
\hline $\mathrm{H}_{2} \mathrm{O}$ & 0 & 0 & 0 & 0.0317 & 0.0317 & 0.0317 \\
\hline $\mathrm{CO}_{2}$ & 0.048 & 0.010 & 0.0107 & 0.0266 & 0.0266 & 0.0263 \\
\hline $\mathrm{CH}_{4}$ & 0.765 & 0.0018 & 0.0160 & 0.0002 & 0.0002 & 0.0002 \\
\hline
\end{tabular}

Figure (4-a) shows variation of the thermal efficiency with the compression ratio. It is clear that the thermal efficiency will be increased with increasing of compression ratio in compressor. It can be observed in this figure that, the thermal efficiency of cycle reaches to its maximum point at each selected value of compression ratio by increasing methane concentration in inlet fuel mixture of lean-burn gas turbine. As shown in figure (4-b), increasing of the compression ratio is accompanied with increasing of the methane concentration in the intake feed at each turbine inlet temperature (TIT). However, it can be observed from combination of figure (4-a) and (4-b), at the same pressure ratio, higher thermal efficiency may be obtained at higher TIT and higher concentration of methane. 


\section{Conclusion}

The objective of this research work has been to introduce an energy recovery system for power generation from coal bed gas of Tabas coal mine of Iran. With the aim of developing more efficient, cost-effective technologies for mitigating and utilizing the diluted coal mine, this paper studied a novel energy recovery system, which can be powered with about $1.6 \%$ methane (volume) in intake mixture. The results indicate that, the methane concentration of ventilation air and also temporal availability of drainage gas should be considered as main factors for developing any power generation system in a coal mine. Based on the obtained results from simulation, 6.193 MW power may be generated from coal bed gas recovery in Tabas coal mine. Therefore, $57 \%$ of total electricity demand of the mine can be supplied by the on-site power generation in this mine. If electricity unit price is considered as 0.09 $\$ / \mathrm{kWh}$ and with purposing total capital investment around 6.7 millions dollars including leanburn gas turbine, ventilation fan, drainage fan, mixer and piping, internal rate of ratio (IRR) and net present value (NPV) of project may be estimated at $41 \%$ and 14.6 millions dollars respectively and its economical feasibility will be supported.
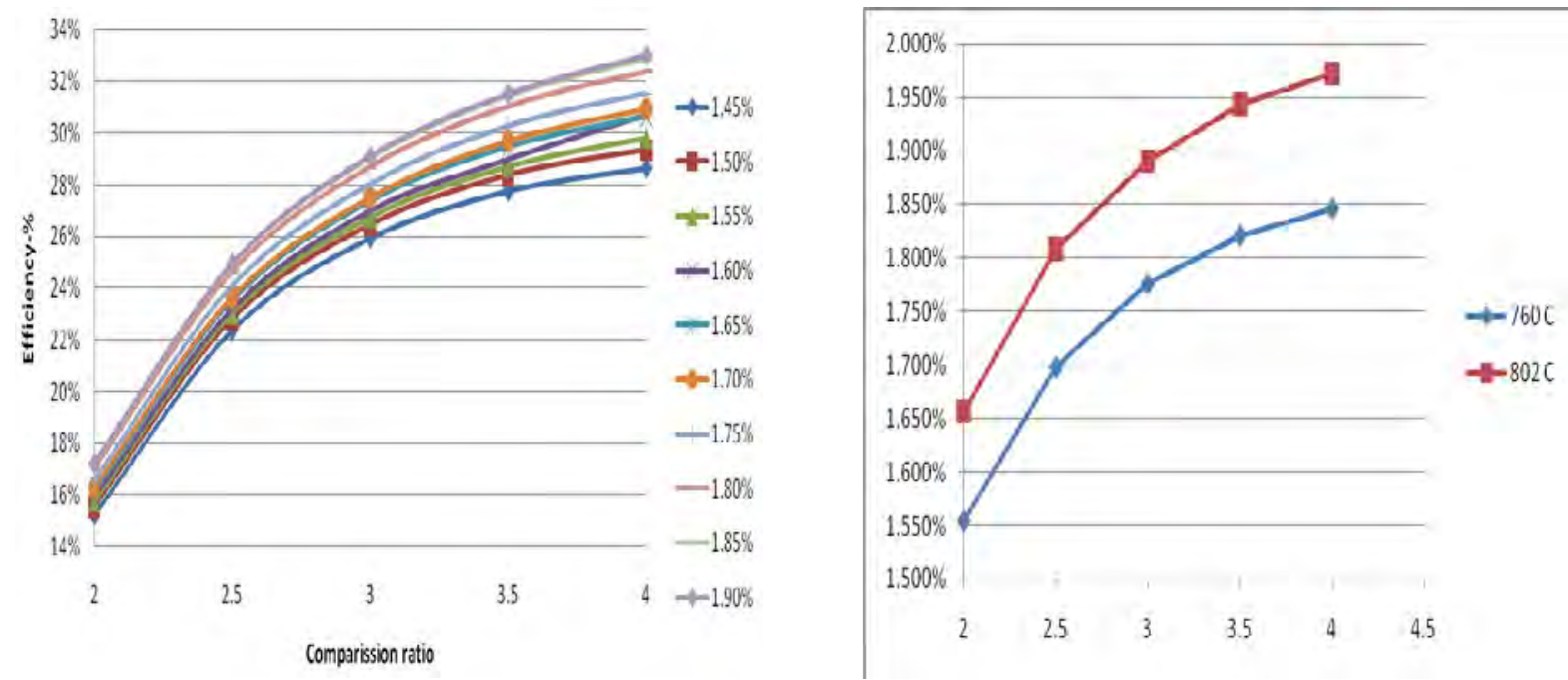

Fig. 4: a) Variation of thermal efficiency with compression ratio b) variation of TIT with compression ratio and different methane concentration

\section{References}

[1] C.J.Bibler, J.S.Marshall, R.C.Pilcher, Status of worldwide coal mine methane emissions and use. International Journal of Coal Geology, 1998, pp.283-310

[2] S.Su, T.Ren, R.Balusu, A.Beath, H. Guo, C.Mallett, Development of Two Case Studies on Mine, Methane Capture and Utilization in China, CSIRO Exploration and Mining report, 2006

[3] K.Markowski, Coalbed methane resource potential and current prospects in Pennsylvania, Int. journal of Geology, 1998, pp.137-159

[4] S.Su, H.Chen, P.Teakle, S.Xue, Characteristics of coal mine ventilation air flows. Journal of Environmental Management, 2008, pp. 44-62

[5] J.Yin, S.Su, X.Xiang Y.Yiwu, Thermodynamic characteristics of a low concentration methane catalytic combustion gas turbine, Applied Energy, 2010, onsite available 
[6] L.Chuan-tong, L.Fa-yangb, S.Jin-di, Thermal economy analysis of utilizing coalmine methane energy, journal of Procedia Earth and Planetary Science, 2009,pp. 1343-1350

[7] S.Su, J.Agnew, Catalytic combustion of coal mine ventilation air methane. Journal of Fuel 2006, pp. 1201-1210

[8] A.Beath, C.W.Mallett. An assessment of mine methane mitigation and utilization technologies. Journal of Progress Combustion Science, 2005, pp.31:123-70.

[9] P.Robert, P. Hesketh, HYSYS - Inductive Method, AspenTech Report, 2003 